\title{
psychological distress in australian case managers working with the unemployed
}

\author{
Richard Goddard \\ Wendy Patton \\ Peter Creed
}

\begin{abstract}
This study reports levels of psychological distress found in a sample of Australian case managers who work with the unemployed. Using a longitudinal survey methodology, 86 case managers employed throughout Australia completed the 12-item General Health Questionnaire (GHQ-12; D. P. Goldberg, 1978) on 2 occasions during 1999. In comparison with other studies investigating psychological wellbeing of both employed and unemployed individuals, case manager respondents in this study reported significantly higher levels of psychological morbidity than levels reported for employed Australians and similar morbidity levels to those reported by unemployed Australians. Skills training seemed to moderate psychological distress levels reported by female case managers.
\end{abstract}

This research was conducted following a time of great change in the way employment services were delivered in Australia. Historically, publicly funded employment services in this country have been delivered directly by the Australian Federal Government through a national employment agency, the Commonwealth Employment Service. In response to high unemployment rates and the prevailing mood of economic rationalization of public expenditures, successive Australian Federal Governments during the 1990s have progressively privatized the delivery of services to the unemployed. The resulting national employment service is known as the Job Network, a term that encompasses a diverse range of welfare, community, and private sector organizations now competing with each other to assist the unemployed in finding employment. Within the Job Network framework, employment services are delivered to the long-term unemployed, that is, to those individuals who have been continuously unemployed for 12 months or more, through an individually focused service-delivery strategy referred to as intensive assistance. It is the well-being of the personnel delivering intensive assistance to the long-term unemployed that is the focus of this study. The

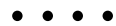

Richard Goddard is an associate lecturer at the School of Learning and Development, and Wendy Patton is an associate professor and acting head of the School. Both are with the Faculty of Education at Queensland University of Technology, Kelvin Grove, Australia. Peter Creed is a senior lecturer in the School of Applied Psychology at Griffith University, Gold Coast, Australia. Correspondence regarding this article should be sent to Wendy Patton, School of Learning and Development, Queensland University of Technology, Victoria Park Road, Kelvin Grove, QId, 4059 AUSTRALIA (e-mail: w.patton@qut.edu.au). 
purpose of this study was to investigate the current state of the psychological wellbeing of personnel whose job description requires them to enter into intensive one-to-one relationships with their unemployed clients to assist them in gaining employment. Such personnel are usually referred to as case managers because the system of support and assistance they offer their clients is in keeping with the case management models of service provision in social work (Moore, 1992) and other medical models of service delivery from which the current Australian employment services model has been developed (Hagen, 1994).

At the beginning of 1999, the Job Network included 150 different organizations that were offering intensive assistance to the more than 240,000 long-term unemployed Australians seeking full-time employment (Australian Bureau of Statistics, 1999). These organizations employ case managers who, collectively, deliver employment services to long-term unemployed individuals through 842 sites within Australia.

In contrast to the copious literature detailing the effects of unemployment on the well-being of Australian and overseas occupational groups (e.g., see Allatt \& Yeandle, 1992; Fryer \& Payne, 1986; Leanna \& Feldman, 1992; Winefield, 1995), there is very little in the way of published work on the topic of well-being in staff who work directly with the unemployed. This point was acknowledged by Kelvin and Jarrett (1985) more than a decade ago, and little has changed since that time. One recent exception is the empirical investigation of burnout in case managers, reported by Goddard and Patton (1998). In their study, a comparison of burnout levels between case managers and non-case managers working with unemployed Australians in shared working environments was presented. Here the researchers found significantly higher levels of burnout in staff who were using a personalized case management approach to assisting clients than in staff who were assisting their unemployed clients by providing over-the-counter services.

From the first introduction, in March 1994, of case management into the Australian system for delivering employment services to the long-term unemployed, the Australian government has recognized that service delivery effectiveness would depend on the ability of individual case managers to adapt to a more intensive and more comprehensive helping service than had ever before been the case in Australia (Commonwealth of Australia, 1994). Although some researchers have argued that using authority and using power are the most crucial factors in influencing the effectiveness of case management (e.g., see Rubin, 1987, pp. 216-217), other researchers suggest that caseload size, level of training, and availability of resources are the most relevant factors influencing case manager effectiveness (Austin, 1990; Hagen, 1994). In particular, it has been recognized that effective case managers would be competent at managing their role across the five core elements of case management-assessment, planning, linking, advocacy, and monitoring/evaluating performance (Employment Assistance Australia, 1995; Hagen, 1994). Appropriate training that identifies and teaches effective management of these core skills could be expected both to improve case manager proficiencies and to increase case manager feelings of self-efficacy and well-being through the reduction of role ambiguities and role conflicts that typically arise in such multifaceted roles. For example, training could be expected to have a particularly 
beneficial effect on case manager well-being through teaching effective strategies for handling the role conflict that inevitably arises from initiating punitive financial sanctions against clients with whom the case manager has been working collaboratively but whose performance has subsequently been evaluated negatively.

In their recent review of subjective well-being research, Diener and his coauthors (Diener, Suh, Lucas, \& Smith, 1999) stressed the point that "personality is one of the strongest and most consistent predictors of subjective well-being" (p. 279). The implications of this for researchers in the field have been pointed out repeatedly. For example, Costa and McCrae (1980, 1987), McCrae (1990), and others (e.g., Brief, Burke, George, Robinson, \& Webster, 1988; Ormel, 1983) have argued that levels of symptom reporting in self-report surveys may be systematically biased through the influence of the personality trait neuroticism on styles of perceiving and reporting physiological and psychological experiences. Watson and Clark (1984) have succinctly described this effect as "the disposition to experience aversive emotional states" (p. 465) and refer to the personality trait neuroticism as "negative affectivity." The implications for researchers conducting survey investigations in the field of well-being center around being able to correctly interpret the results that are obtained. McCrae (1990) argues that "measuring neuroticism should be considered as an adjunct to any measurement of stress, in order to provide a context in which reports of stressful events and conditions can be interpreted" (p. 240). This study follows McCrae's advice and concurrently investigates the personality dimension of neuroticism in all survey respondents.

\section{METHOD}

\section{Design}

As part of a larger study investigating burnout in Australian employment service personnel during and after the transition to a new employment service delivery system, the primary objective of this study was to contribute to the evaluation of the overall state of health and well-being of Australian Job Network personnel during 1999. For this reason, particular hypotheses about overall case manager well-being were not stipulated; however, the study has also focused on the influence that skills training might have on case manager well-being. Given the multifaceted nature of the case manager role and the expected contribution that role competence and reduced role conflict could be expected to have on case manager well-being, this study hypothesized that case managers who have undertaken formal skills training will have significantly lower mean Likert scores on the 12-item General Health Questionnaire (GHQ-12; Goldberg, 1978), corresponding to a lower distress level, than case managers who indicate that they have not undertaken such training.

\section{Participants}

Participants were employees of employment service organizations whose primary role was to provide intensive assistance to Australian individuals who had been 
unemployed for more than 12 months. Each organization was, at the time the surveys were conducted, officially recognized as being a member of the national employment service currently operating in Australia called the Job Network. The principal duty of all the participants in this study was to individually assist their unemployed clients to obtain employment.

A total of 86 case managers took part in the first phase (T1) of this study by completing and returning the survey instruments described later in this article. Case managers surveyed at $\mathrm{T} 1$ had an average age of 38 years $(S D=9.70)$ and had been employed for approximately 29.4 months $(S D=25.45)$ as case managers. Sixty-five percent $(n=56)$ of the case managers surveyed at T1 were female, a percentage that reflects the gender proportions typically found in this industry.

Participants were surveyed again approximately 5 months after the first survey. Eighty-one percent $(n=70)$ of case managers surveyed at Tl returned surveys during the second phase (T2). The higher percentage of women observed at T1 was maintained at T2 (i.e., $63 \%$ women). Table 1 summarizes general demographic information collected at $\mathrm{T} 1$ and $\mathrm{T} 2$.

\section{Instruments}

Psychological well-being. The current level of well-being was assessed using the 12-item GHQ-12 (Goldberg, 1978). This is a self-administered, point-in-time screening test, designed to detect psychiatric disorders, that has been extensively used in a variety of occupational and community settings as a screening measure for psychological ill health (see Banks et al., 1980; Boardman, 1987; Burvill \& Knuiman, 1983; Firth-Cozens, 1990). The GHQ-12 has been validated for use with Australian

\section{TABLE 1}

\section{Demographic and Workload Variables Reported by Case Manager Respondents at T1 and T2}

\begin{tabular}{lrrr}
\hline \hline Variable & $\boldsymbol{M}$ & $\boldsymbol{S} \boldsymbol{}$ & Range \\
\hline T1 $(N=86)$ & & & \\
Age (years) & 38.01 & 9.70 & $21-54$ \\
Months employed & 29.41 & 25.45 & $1-100$ \\
Average weekly hours & 37.45 & 7.59 & $16-50$ \\
$\quad$ Total caseload & 132.43 & 80.64 & $34-670$ \\
Active caseload & 89.62 & 43.39 & $10-230$ \\
T2 $(N=70)$ & & & \\
Age (years) & 38.19 & 9.86 & $21-55$ \\
Months employed & 30.84 & 20.85 & $6-96$ \\
Average weekly hours & 37.00 & 7.52 & $10-45$ \\
Total caseload & 125.86 & 45.36 & $2-250$ \\
Active caseload & 87.62 & 34.57 & $2-180$ \\
\hline
\end{tabular}

Note. $\mathrm{T} 1$ = first phase of study; $\mathrm{T} 2$ = second phase of study. 
respondents (Tennant, 1977). In this study, both the binary and Likert methods of scoring responses were used. Binary scores of 2 or more from the 12 items were taken to represent cases of psychological distress or morbidity. This cutoff criterion is commonly used and reported in the literature (e.g., Tennant, 1977). In the Likert scoring system, higher scores correspond to increasing psychological pathology. Goldberg and Williams (1988) have published an extensive presentation of the psychometric properties of the GHQ-12 that are more than satisfactory. In the present study, coefficient alpha was calculated to be .92 on both occasions that the instrument was administered.

Neuroticism. Neuroticism was measured by administering the short form of the revised Eysenck Personality Questionnaire (EPQ-R/s; Eysenck \& Eysenck, 1991). The EPQ-R/s is a 48-item instrument that asks respondents to make yes or no decisions on items describing behaviors or responses typical of one of four major dimensions of personality. The Neuroticism subscale from this instrument contains 12 items. The technical manual reports acceptable reliability coefficients for this subscale, .88 for men and .85 for women, and discusses the validity of the instrument with reference to 40 years of development of the Eysenck Personality Scales. In the present study, coefficient alpha for the Neuroticism subscale was .78 for men and .81 for women.

\section{Procedure}

Participants completed the aforementioned materials as part of a larger longitudinal study that used a postal survey to investigate case manager burnout. The GHQ-12 was first administered by mail between March and May 1999 (T1), and again between August and October 1999 (T2). The EPQ-R/s was administered at T1.

\section{RESULTS}

\section{Demographics, Workload Indicators, and Gender Differences}

Eighty-one percent of case managers who returned surveys at T1 returned surveys at T2 and satisfied the criterion that they were still undertaking case manager duties. No attrition bias was identified for 16 respondents who dropped out between the initial and subsequent survey.

Mean case manager respondent age, average months employed as a case manager, and mean case manager workload indicators at both $\mathrm{T} 1$ and $\mathrm{T} 2$ are presented in Table 1. Univariate analyses of variance (ANOVAs) indicated no significant differences between $\mathrm{T} 1$ and $\mathrm{T} 2$ on any of the demographic or workload measures presented in Table 1.

A further series of ANOVAs indicated no significant gender differences on any of demographic, workload, or dependent variables at either T1 or T2.

\section{Neuroticism}

Mean case manager scores for Neuroticism were $4.23(S D=2.96)$ for men and 4.73 $(S D=3.15)$ for women. These scores were consistent with the corresponding age 
group norms presented in the technical manual (Eysenck \& Eysenck, 1991; p. 23), two-tailed $t$ tests not reaching significance at the .05 level.

\section{The Psychological Well-Being of Australian Case Managers}

Using the binary scoring criterion and the $1 / 2$ cutoff criterion described previously, $51 \%(n=44)$ of case managers surveyed at T1 endorsed responses on the GHQ-12 indicating prevailing or imminent psychological ill health. At T2, this percentage had risen to $57 \%$. However, the Wilcoxon matched-pairs signed-ranks test indicated that the increase was not significant $(z=0.69, p>.05)$. Table 2 presents psychological morbidity case rates and mean GHQ-12 Likert scores for the total sample as well as for male and female case managers participating in this study. Overall mean GHQ-12 Likert scores for T1 and T2 remained at similar levels, and a breakdown by gender indicated that observed changes in the GHQ-12 Likert scores between T1 and T2 were not significant.

A comparison of the case rates and the mean GHQ-12 Likert scores found in this study was made with the results of three other studies that investigated psychological morbidity in other Australian population cohorts. The Australian Longitudinal Survey (ALS), conducted between 1985 and 1988, systematically investigated psychological well-being of Australians aged 16 to 25 years. The ALS surveyed respondents annually and, as a result, Graetz (1993) and others (e.g., Morrell, Taylor, Quine, Kerr, \& Western, 1994) have reported annual psychological morbidity rates for employed and unemployed respondent subgroups from this study. A series of chi-square tests indicated that the case manager morbidity rate found in our study at Tl was significantly higher than the prevalence of psychological morbidity reported for employed respondents throughout the 4 years of the ALS and higher than the case rate reported for unemployed respondents in 2 of the 4 years (Graetz, 1993). These comparisons are shown in Table 2 . As already indicated, case manager morbidity rates at $\mathrm{T} 2$ had risen from $51 \%$ to $57 \%$, and although this increase was not significant, further chi-square tests comparing morbidity case rates at T2 with the ALS results were conducted. Case manager morbidity case rates at T2 were found to be significantly higher than the case rate for unemployed ALS respondents in all 4 years that the survey was conducted.

In a second comparison with a group of long-term unemployed Australian adults (Patton \& Donohue, 1998), the mean GHQ-12 Likert scores for case managers in this study at T1 and T2 were significantly higher, corresponding to higher psychological distress, than the equivalent scores reported for the unemployed adults, $t(122)$ $=2.29, p<.05$, and $t(106)=2.59, p<.05$, two-tailed tests respectively (see Table 2 ).

A third comparison was made with the results presented in Winefield, Tiggemann, and Winefield's (1991) study, which compared the psychological impact of engaging in satisfactory work with the impact of unsatisfactory work and unemployment. Mean GHQ-12 Likert scores for case managers at both T1 and T2 were significantly higher than the scores reported in Winefield et al.'s study for the employed workers who found their work satisfactory, $t(501)=5.70, p<.001$, and $t(485)=6.19, p<.001$, 
TABLE 2

\section{Comparison of Case Manager Psychological Morbidity Estimated by the GHQ-12 at T1 With Levels at T2 and Statistics Reported by Other Australian Studies}

\begin{tabular}{|c|c|c|c|c|}
\hline \multirow[b]{3}{*}{ Study } & \multicolumn{4}{|c|}{ Level of Psychological Morbidity } \\
\hline & \multicolumn{2}{|c|}{ Case Rate } & \multicolumn{2}{|c|}{ GHQ-12 } \\
\hline & Respondents & $\%$ & $M$ Likert Score & $S D$ \\
\hline \multicolumn{5}{|l|}{$\begin{array}{l}\text { The present study } \\
\text { T1-March-May } 1999 \\
\text { Full sample (mean age } 38\end{array}$} \\
\hline years) & 86 & 51 & 12.35 & 6.53 \\
\hline Male case managers & 30 & 50 & 12.40 & 7.36 \\
\hline Female case managers & 56 & 52 & 12.32 & 6.11 \\
\hline \multicolumn{5}{|l|}{ T2-August-October 1999} \\
\hline $\begin{array}{c}\text { Full sample (mean age } 38 \\
\text { years) }\end{array}$ & & & & \\
\hline $\begin{array}{l}\text { years) } \\
\text { Male case managers }\end{array}$ & $\begin{array}{l}70 \\
26\end{array}$ & $\begin{array}{l}57 \\
65\end{array}$ & $\begin{array}{l}12.83 \\
14.62\end{array}$ & $\begin{array}{l}6.38 \\
7.43\end{array}$ \\
\hline $\begin{array}{l}\text { Male case managers } \\
\text { Female case managers }\end{array}$ & 26 & 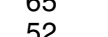 & 14.02 & 7.43 \\
\hline \multicolumn{5}{|l|}{ Graetz (1993); Australian } \\
\hline \multirow{2}{*}{\multicolumn{5}{|c|}{$\begin{array}{l}\text { Longitudinal Survey data } \\
\text { Employed throughout }\end{array}$}} \\
\hline & & & & \\
\hline Surveyed in 1985 & 2,647 & ${ }^{a} 27^{\star \star \star}$ & 9.03 & - \\
\hline Surveyed in 1986 & 2,647 & a2 $24^{\star * *}$ & 8.81 & - \\
\hline Surveyed in 1987 & 2,300 & a22 $2^{\star \star *}$ & 8.76 & - \\
\hline Surveyed in 1988 & 1,978 & a22 $2^{\star \star \star}$ & 8.81 & - \\
\hline \multicolumn{5}{|l|}{ Unemployed throughout } \\
\hline Surveyed in 1985 & 76 & $43 \mathrm{~ns}$ & 10.66 & - \\
\hline Surveyed in 1986 & 76 & $45 \mathrm{~ns}$ & 11.29 & - \\
\hline Surveyed in 1987 & 42 & ${ }^{\mathrm{a}} 38^{*}$ & 11.88 & - \\
\hline Surveyed in 1988 & 33 & a $36^{\star \star}$ & 11.00 & - \\
\hline \multicolumn{5}{|l|}{ Patton \& Donohue (1998) } \\
\hline \multicolumn{5}{|l|}{$\begin{array}{l}\text { Unemployed Australian } \\
\text { adults }\end{array}$} \\
\hline Full sample (ages 19-61) & 38 & - & b9.34* & 7.06 \\
\hline \multicolumn{5}{|l|}{ Winefield et al. (1991) } \\
\hline \multicolumn{5}{|l|}{$\begin{array}{c}\text { Young Australians (mean } \\
\text { age } 22.6 \text { years) }\end{array}$} \\
\hline \multicolumn{5}{|l|}{$\begin{array}{l}\text { Unemployed (mean } \\
\text { duration } 11.36\end{array}$} \\
\hline months) & 40 & - & 11.49 & 6.32 \\
\hline Satisfied employed & 417 & - & b $9.27^{\star \star \star *}$ & 4.03 \\
\hline Dissatisfied employed & 45 & - & 11.74 & 6.59 \\
\hline
\end{tabular}

Note. See Table 1 Note. GHQ-12 = 12-item General Health Questionnaire; dashes = not reported.

${ }^{a *} p<.05 .{ }^{* \star} p<.01 .{ }^{* * *} p<.001$. Asymmetrical significance. ${ }^{{ }^{*}} p<.05 .{ }^{* \star *} p<.001$. Twotailed significance. Significance levels indicate differences from GHQ-12 scores recorded by the present study at $\mathrm{T} 1$. 
two-tailed tests respectively, and not significantly different from the scores of dissatisfied workers or the unemployed (see Table 2).

\section{Training}

At T1, almost two thirds of case managers surveyed (65.1\%) indicated that they had not undertaken a formal skills training course pertinent to their case management duties, whereas one third indicated that they had undertaken such training. One respondent failed to answer this question. A two-factor ANOVA with gender and skills training as between-subject factors and GHQ-12 Likert scores at T1 as the dependent variable found significant main effects for skills training $F(1,81)$ $=5.40, p<.05$, and a significant Training $\times$ Gender interaction $F(1,81)=4.18$, $p<.05$. Post hoc analyses indicated that the mean score of case managers who had undertaken training was significantly lower, corresponding to lower psychological distress, than was the mean score for those who had not. A breakdown of this finding by gender indicated that training was associated with significantly lower distress levels for female case managers, $t(53)=3.48, p<.001$, but not for male case managers. For men, training was associated with a marginally higher, but statistically equivalent, mean GHQ-12 score in comparison with the mean score of untrained men, $t(28)=0.65, p>.05$. Table 3 presents a breakdown of mean GHQ-12 Likert scores at T1 by training and gender.

\section{TABLE 3}

\section{Levels of Case Manager Skills Training Reported by Respondents at T1 and Concurrent Psychological Morbidity Levels for Male and Female Case Managers}

\begin{tabular}{lccc}
\hline & & \multicolumn{2}{c}{$\begin{array}{c}\text { Level of Psychological } \\
\text { Morbidity GHQ-12 }\end{array}$} \\
\cline { 3 - 4 } Formal Skills Training & Respondents & M Likert Score & SD \\
\hline No training undertaken & 24 & 12.08 & 7.23 \\
$\quad$ Men & 32 & 14.69 & 6.31 \\
$\quad$ Women & 56 & 13.57 & 6.78 \\
$\quad$ Total & 6 & 13.67 & 8.45 \\
Skills training undertaken & 23 & 9.52 & 3.86 \\
$\quad$ Men & 29 & 10.38 & 5.23 \\
$\quad$ Women & 1 & & \\
$\quad$ Total & & &
\end{tabular}

Note. See Table 2 Note. 


\section{DISCUSSION}

\section{Psychological Distress in Australian Case Managers}

The GHQ-12 is an instrument widely accepted as a reliable screening tool to detect respondents who are currently suffering from or who are likely to suffer a psychological or psychiatric illness. In this study, the GHQ-12 has identified significant levels of psychological morbidity. The results ensuing from the standard binary scoring methodology point to a high level of pathology in case manager personnel relative to levels reported in other studies investigating the well-being of Australians. More than one half $(51 \%)$ of the case managers surveyed at Tl were identified as either suffering from, or to be at serious risk of developing, a psychological illness. This case rate had increased to $57 \%$ at T2. Although this increase was not statistically significant, the finding is confirmation of the stability of the study's observations.

Comparisons of mean case manager GHQ-12 Likert scores with those published in other studies support the conclusion that psychological morbidity in the case manager sample is high. Mean case manager Likert scores at both T1 and T2 corresponded to levels commonly reported for highly stressed occupational groups, such as hospital and community-based mental health staff (Prosser et al., 1996), and the unemployed (Patton \& Donohue, 1998; Winefield et al., 1991).

The comparisons with unemployed Australians, presented in Table 2 , are particularly interesting because they contrast case manager morbidity rates with morbidity rates in the case managers' primary client group, the long-term unemployed. The results presented in Table 2 suggest a higher morbidity level in case managers than is commonly found in some unemployed adult populations (Patton \& Donohue, 1998) and statistically equivalent morbidity levels to those levels reported in other unemployed populations (Winefield et al., 1991). Such findings are consistent with explanations of psychological strain, in terms of the pursuit of an equality of investments and returns in social exchanges, that is hypothesized to occur in helping relationships (Schaufeli, Van Dierendonck, \& Van Gorp, 1996).

By following the advice of McCrae (1990) and others and concurrently investigating the stable personality trait neuroticism, this study has demonstrated that the case manager group being investigated was no different on the personality dimension neuroticism than the normative population. This finding has importance in qualifying the results presented because it suggests that the significant psychological morbidity levels found in this case manager sample do not reflect an underlying disposition of case managers to interpret stressful events more negatively than the general population.

\section{Influence of Training on Case Manager Distress}

The influence that the presence of formal skills training might have on case manager distress levels was a particular interest in this investigation. It was hypothesized that appropriate skills training might be associated with lower morbidity levels. The 
results supported this hypothesis. The observation was expected that the mean GHQ12 Lickert score would be significantly lower for the one third of case managers who reported that they had undertaken formal case manager skills training than the mean GHQ-12 Lickert score would be for the two thirds of the managers who had not undertaken training. What was unexpected was the interaction of this result with gender. Quite unexpectedly, female case managers responded to training as hypothesized, whereas training seemed to have no influence on the well-being of male case managers. One explanation of this finding might be that there are differences in the roles that male and female case managers are expected to undertake within the Job Network. Another potential explanation might be associated with systematic differences in the training that is offered to men and women. Because this study did not investigate a particular skills training program but relied on the case manager respondents to nominate whether they had participated in any formal training or educational program that had content pertinent to their case manager duties, all potential explanations for the finding should remain hypothetical and tentative until the finding has been replicated. Regardless of the explanation, methodologically the results reinforce the importance of adopting research methodologies that systematically investigate gender in investigations into the influence of training on well-being.

\section{Implications for Employment Counselors}

The results of this study strongly suggest that providing human services to unemployed individuals can result in serious levels of psychological distress for case managers. These results, as well as having serious implications for the on-going well-being of case managers working with the unemployed, have implications for the management of well-being levels in other groups of personnel who work in similar intensive, oneto-one relationships with clients who are unemployed. In particular, employment counselors, an occupational group whose role typically involves the development and maintenance of relationships with individuals who are unemployed, may be exposed to a serious risk of experiencing elevated distress levels when a large proportion of their caseload involves counseling individuals experiencing long-term unemployment. Only a systematic investigation of employment counselors working predominantly with the long-term unemployed will address this question; however, elevated stress levels are by no means unlikely. The case management role involves core activities, some of which bear close resemblance to elements of problem-focused counseling strategies such as Ivey's (1988) intentional interview process. Furthermore, the unemployed, as a group, have repeatedly been identified as experiencing higher levels of psychopathology than societal norms (Fryer \& Payne, 1986; Winefield, 1995), suggesting that work demands arising from employment counseling, which focuses on this group of clients, may well be, on average, above the demands of working with other client groups. On the basis of the serious levels of psychological morbidity found by the present study, future research into the well-being of employment counselors who work with the unemployed is recommended. 
In conclusion, this study has investigated psychological distress in personnel working directly with the unemployed and, in doing so, has begun to address the dearth of literature in this area. The results are indicative of significant levels of psychological distress within the section of the Australian Job Network responsible for delivering services to one of the most severely disadvantaged groups of unemployed individuals, the long-term unemployed. It is clear that psychological distress in personnel delivering intensive assistance to the unemployed is a significant phenomenon, one that has serious implications for the evaluation of service designed to assist unemployed individuals and for the organizations responsible for maintaining the well-being of the personnel who deliver these services.

\section{REFERENCES}

Allatt, P., \& Yeandle, S. (1992). Youth unemployment and the family: Voices of disordered times. London: Routledge.

Austin, C. D. (1990). Case management: Myths and realities. Families in Society, 71, 398-405.

Australian Bureau of Statistics. (1999). Labour force survey: June 1999. Canberra, Australian Capital Territory: Australian Government Publishing Service.

Banks, M. H., Clegg, C. W., Jackson, P. R., Kemp, N. J., Stafford, E. M., \& Wall, T. D. (1980). The use of the General Health Questionnaire as an indicator of mental health in occupational studies. Journal of Occupational Psychology, 53, 187-194.

Boardman, A. P. (1987). The General Health Questionnaire and the detection of emotional disorder by general practitioners: A replicated study. British Journal of Psychiatry, 151, 373-381.

Brief, A. P., Burke, M. J., George, J. M., Robinson, B. S., \& Webster, J. (1988). Should negative affectivity remain an unmeasured variable in the study of job stress? Journal of Applied Psychology, 73, 193-198.

Burvill, P. W., \& Knuiman, M. W. (1983). Which version of the General Health Questionnaire should be used in community studies? Australian and New Zealand Journal of Psychiatry, $134,508-515$.

Commonwealth of Australia. (1994). Working nation: Policies and programs. Canberra, Australian Capital Territory: Australian Government Publishing Service.

Costa, P. T., Jr., \& McCrae, R. R. (1980). Somatic complaints in males as a function of age and neuroticism: A longitudinal analysis. Journal of Behavioral Medicine, 3, 245-257.

Costa, P. T., Jr., \& McCrae, R. R. (1987). Neuroticism, somatic complaints, and disease: Is the bark worse than the bite? Journal of Personality, 55, 299-316.

Diener, E., Suh, E. M., Lucas, R. E., \& Smith, H. L. (1999). Subjective well-being: Three decades of progress. Psychological Bulletin, 125, 276-302.

Employment Assistance Australia. (1995). Case managers' handbook. Canberra, Australian Capital Territory: Australian Government Printing Service.

Eysenck, H. J., \& Eysenck, S. B. G. (1991). Manual of the Eysenck Personality Scales (EPS Adult). London: Hodder \& Stoughton.

Firth-Cozens, J. (1990). Sources of stress in women junior house officers. British Medical Journal, 301, 89-91.

Fryer, D. M., \& Payne, R. L. (1986). Being unemployed: A review of the literature on the psychological experience of unemployment. In C. L. Cooper \& I. Robertson (Eds.), International review of industrial and organisational psychology (pp. 235-278). Chichester, England: Wiley.

Goddard, R. C., \& Patton, W. (1998). A comparison between burnout levels of case management staff and non-case management staff working directly with the unemployed. In E. Carson, A. Jamrozik, \& T. Winefield, (Eds.), Unemployment: Economic promise and political will (pp. 227-236). Brisbane, Australia: Australian Academic Press. 
Goldberg, D. P. (1978). Manual of the General Health Questionnaire. Slough, England: National Foundation for Education Research.

Goldberg, D. P., \& Williams, P. (1988). A user's guide to the General Health Questionnaire. Windsor, England: National Foundation for Education Research.

Graetz, B. (1993). Health consequences of employment and unemployment: Longitudinal evidence for young men and women. Social Science and Medicine, 36, 715-724.

Hagen, J. L. (1994). JOBS and case management: Developments in 10 states. Social Work, 39, 197-205.

Ivey, A. E. (1988). Intentional interviewing and counseling: Facilitating client development. Pacific Grove, CA: Brooks/Cole.

Kelvin, P., \& Jarrett, J. E. (1985). Unemployment: Its social psychological effects. Cambridge, England: Cambridge University Press.

Leanna, C. R., \& Feldman, D. C. (1992). Coping with job loss: How individuals, organizations, and communities respond to layoffs. New York: Lexington Books.

McCrae, R. R. (1990). Controlling neuroticism in the measurement of stress. Stress Medicine, 6, $237-241$.

Moore, S. (1992). Case management and the integration of services: How service delivery systems shape case management. Social Work, 37, 418-423.

Morrell, S., Taylor, R., Quine, S., Kerr, C., \& Western, J. (1994). A cohort study of unemployment as a cause of psychological disturbance in Australian youth. Social Science and Medicine, 38, $1553-1564$.

Ormel, J. (1983). Neuroticism and well-being inventories: Measuring traits or states? Psychological Medicine, 13, 165-176.

Patton, W., \& Donohue, R. (1998). Coping with long-term unemployment. Journal of Community \& Applied Social Psychology, 8, 331-343.

Prosser, D., Johnson, S., Kuipers, E., Szmukler, G., Bebbington, P., \& Thornicroft, G. (1996). Mental health, burnout and job satisfaction among hospital and community-based mental health staff. British Journal of Psychiatry, 169, 334-337.

Rubin, A. (1987). Case management. In A. Minahan (Ed.-in-Chief), Encyclopedia of social work, (18th ed., pp. 212-222). Silver Spring, MD: National Association of Social Workers.

Schaufeli, W. B., Van Dierendonck, D., \& Van Gorp, K. (1996). Burnout and reciprocity: Towards a dual-level social exchange model. Work \& Stress, 10, 225-237.

Tennant, C. (1977). The General Health Questionnaire: A valid index of psychological impairment in Australian populations. Medical Journal of Australia, 2, 392-394.

Watson, D., \& Clarke, L. A. (1984). Negative affectivity: The disposition to experience aversive emotional states. Psychological Bulletin, 96, 465-490.

Winefield, A. H. (1995). Unemployment: Its psychological costs. In C. L. Cooper \& I. T. Robertson (Eds.), International review of industrial and organizational psychology (pp. 51-84). Chichester, England: Wiley.

Winefield, A. H., Tiggemann, M., \& Winefield, H. R. (1991). The psychological impact of unemployment and unsatisfactory employment in young men and women: Longitudinal and crosssectional data. British Journal of Psychology, 82, 473-486. 